\title{
On the impact of impurities on the densification of polar firn
}

\author{
M.W. Hörhold ${ }^{\text {a, }}$, T. Laepple ${ }^{\text {a }}$, J. Freitag ${ }^{\text {a,* }}$, M. Bigler ${ }^{\text {b }}$, H. Fischer ${ }^{\text {b }}$, S. Kipfstuhl ${ }^{\text {a }}$ \\ a Alfred Wegener Institute for Marine and Polar Research, Am Handelshafen 12, D-27570 Bremerhaven, Germany \\ b Climate and Environmental Physics, Physics Institute E' Oeschger Centre for Climate Change Research, University of Bern, Switzerland
}

\section{A R T I C L E I N F O}

\section{Article history:}

Received 10 August 2011

Received in revised form 19 December 2011

Accepted 20 December 2011

Available online 25 February 2012

Editor: P. DeMenocal

\section{Keywords:}

polar firn density

densification

impurity

density variability

\begin{abstract}
A B S T R A C T
Understanding polar firn densification is crucial for reconstructing the age of greenhouse gas concentrations extracted from ice cores, and for the interpretation of air in ice as a dating tool or as a climate proxy. Firn densification is generally modeled as a steady burial and sintering process of defined layers, where the structure of the layering is maintained along the whole firn and ice column. However, available high-resolution density data, as well as firn air samples, question this picture and point to a lack of understanding of firn densification. Based on analysis of high-resolution density and calcium concentration records from Antarctic and Greenland ice cores, we show for the first time that also impurities may have a significant impact on the densification. Analysis of firn cores shows a correlation between density and the calcium ion $(\mathrm{Ca}++)$ concentration, and this correlation increases with depth. The existence of this relationship is independent of the local climatic conditions at the core sites analyzed. The strong positive correlation between the density and the logarithm of $\mathrm{Ca}++$ concentration indicates that impurities induce softening and lead to faster densification over a wide range of concentrations. In one core, the impurity effect manifests itself so strongly that the density develops a seasonal cycle closely following the seasonal cycle of $\mathrm{Ca}++$. Our results clearly show that the structure of the firn layering changes with depth and suggest that the increased variability in density observed in deep firn, recently described as a universal feature of polar firn, may arise from the influence of $\mathrm{Ca}++$ and/or other impurities. The impurity effect is likely to have direct implications on our understanding of glacial firn densification and on glacial gas age estimates.
\end{abstract}

(c) 2012 Elsevier B.V. All rights reserved.

\section{Introduction}

As snow accumulates on the surface of the large ice sheets in Greenland and Antarctica, the firn below compacts to ice, a process fundamental to glaciology and to the reconstruction of paleoclimate. When the density of firn increases roughly by a factor of three from $\sim 300 \mathrm{~kg} / \mathrm{m} 3$ at the surface to more than $820 \mathrm{~kg} / \mathrm{m} 3$, all pores in the firn are closed off and air, younger than the surrounding ice, is entrapped in air bubbles. This typically happens at depths between 50 and $120 \mathrm{~m}$, at which the ice is already a few hundred to a few thousand years old (Schwander et al., 1997).

Knowledge of the age difference between ice and air is necessary to reconstruct the age of the air extracted from ice cores, with climate implications including the relative lead or lag between temperature and greenhouse gas concentrations during climate transitions. Recently, it has been shown that the entrapped air in the ice is also related to local orbital insolation variations (Bender, 2002; Raynaud

\footnotetext{
* Corresponding author at: Alfred-Wegener-Institute for Marine and Polar Research, Am Handelshafen 12, D-27570 Bremerhaven, Germany. Tel.: + 494714831 1197; fax: + 494714831

E-mail address: Johannes.Freitag@awi.de (J. Freitag).

1 Present address: Helmholtz-Zentrum Dresden-Rossendorf, Bautzner Landstrasse 400, D-01328 Dresden, Germany.
}

et al., 2007). The orbital signal in the ice would permit dating ice core records independently from other methods (Kawamura, 2009; Kawamura et al., 2007) if the complete chain of processes involved in the signal formation at the surface, in the firn column and at the firn-ice transition was understood. Presently, it is believed that local insolation affects the microstructure of the firn at the surface, which is unaltered during the densification and recrystallization process in the firn. However, fundamental processes controlling densification and therefore air entrapment in ice are not fully understood.

Several firn models attempt to predict firn densification and are based on the concept of isothermal hot pressure sintering. The models consider the overburden pressure as driving force (Kameda et al., 1994), the microscopic approach for the geometrical theory of pressure sintering of mono-sized spherical powders (Arnaud et al., 2000; Kameda et al., 1994) or couple the firn densification with heat diffusion (Goujon et al., 2003). Critical densities, at which the main densification process changes from grain boundary sliding to plastic deformation (Arnaud et al., 2000; Salamantin et al., 2006) are included in order to take care of the changing densification rate with depth. Main focus of the model studies is the prediction of air close-off within the firn column and thus detection of the age of the entrapped air (Arnaud et al., 2000; Goujon et al., 2003).

However, for several ice cores located in very low accumulation rate areas (such as Dome C or Vostok), a systematic mismatch 
between the observed nitrogen isotopic composition during glacial periods and the predictions from firn densification models was found (Landais et al., 2006; Sowas et al., 1992). For example, the comparison of two EPICA gas records from Dome $C$ and Dronning Maud Land (Loulergue et al., 2007) revealed, that the firn densification models overestimate the age difference between the ice and the gas phase at Dome $\mathrm{C}$ during the last glacial period. Since all firnification models are tuned to describe modern conditions encountered in polar firn, this essentially represents a modern analog problem.

Current firn models do not account for small scale variability within the firn column and the few existing high-resolution measurements question the current conception of firn densification (i.e. Freitag et al., 2004; Gerland et al., 1999; Hörhold et al., 2011). Firn is extremely stratified with layer thicknesses of less than $10 \mathrm{~cm}$. Density, hardness, grain size and grain shape, for example, vary strongly between layers. This layering induces a distinct variability in the density profile, which is not captured by the common density measurements on a meter resolution or by current firnification models.

High-resolution measurements of firn density by Gamma- or X-ray absorption have been performed but are still scarce (Freitag et al., 2004; Gerland et al., 1999; Hori et al., 1999).

In a recent study Hörhold et al. (2011) compiled high-resolution density records of 17 firn cores from Greenland and Antarctica, nearly all reaching the firn-ice transition. The observed mean density profiles agree well with the density profiles predicted by the firn densification model most commonly used in the literature (Herron and Langway, 1980). However, the analysis of the density variability revealed a paradoxical behavior (Freitag et al., 2004; Gerland et al., 1999; Hörhold et al., 2011). The variability in density first decreases with depth and time, but unlike in a homogeneous medium, it increases again in the middle of the firn column.

Freitag et al. (2004) explained this feature as "cross-over" behavior, where initially low-density layers reach similar density values as initially high-density layers, the former compacting faster than the latter. This view is supported by findings of Gerland et al. (1999) and Fujita et al. (2009). However, a well-tested explanation, supported by detailed data comparison of density of layers from the near surface to layers from greater depths, is still lacking.

Firn cores with sufficient annual snow accumulation show a seasonal cycle in density (Bigler et al., 2002). The seasonal temperature cycle is thought to be responsible for the creation of density variability (Alley, 1988; Gow, 1965; Zwally and Li, 2002). Firn models usually predict that seasonal variations in density decrease and fade out slowly with depth in the later stage of densification (Zwally and Li, 2002). This behavior, however, is opposite to the observations (Hörhold et al., 2011), which show an increase in density variability with depth. This observation leads to the hypothesis of this study that densification might be influenced by impurities. As many impurity species show seasonal cycles (Bigler et al., 2002; Rasmussen et al., 2006; Sommer et al., 2000; Svensson et al., 2005) an influence on the densification could explain the occurrence of (seasonal) varying density layers at greater depth.

In this paper we report for the first time a close correlation between density and impurities that evolves with depth. From the impurity data set available we have chosen the calcium ion $(\mathrm{Ca}++)$ because it is available for the largest number of cores and shows a well described seasonality in Greenland and Antarctica. Note, however, that also other impurities may have an influence on firn densification. To demonstrate the active role impurities play in the evolution of density in polar firn, we first analyze density and $\mathrm{Ca}++$ for a Greenland core in which the seasonal cycles of both parameters are most distinct. Finally we analyze all available high-resolution density and $\mathrm{Ca}++$ records to provide additional evidence, independent of the presence of a seasonal cycle, that impurities affect densification with increasing depth and time, and modify the initial structure of the layering in firn.

\section{Methods and data}

The density data of the 5 firn cores analyzed in this study are described in Hörhold et al. (2011). The original density data, measured by gamma-absorption at $1-5 \mathrm{~mm}$ resolution, were homogenized by manually removing core breaks and linearly interpolating over the resulting gaps. The depth scale was converted into water equivalent depth (w.e.) and averaged to $5 \mathrm{~mm}$ w.e. resolution. Details of the gamma-absorption method are given in Wilhelms (1996, 2000). Information about the position of the coring sites and their mean annual temperature and accumulation rates are summarized in Table 1.

High-resolution impurity data measured by Continuous Flow Analysis (CFA) were available for the cores B20 (Bigler et al., 2002) and B29 (Sommer, 1996) from Greenland and the cores B31, B32 und B33 (Sommer et al., 2000) from Antarctica. As only the Ca++ data were available for all five cores, we focused the study on this species. From these 5 CFA records, B29 exhibits the most persistent seasonal cycle in $\mathrm{Ca}++$ with a peak generally centered in spring time in Greenland (Bigler et al., 2002; Rasmussen et al., 2006). In Antarctica other major impurity species appear to be in phase with $\mathrm{Ca}++$ (Sommer et al., 2000).

The $\mathrm{Ca}++$ data were homogenized similarly to the density data. Finally, the data were averaged to a resolution of $5 \mathrm{~mm}$ w.e., and a small number of outliers $(<1 \%)$ were removed from the $\mathrm{Ca}++$ datasets by visually investigating the histogram. Low frequency variations in the density records were removed using a finite impulse response high pass filter (Bloomfeld, 1976) (cut-off frequency $0.5 \mathrm{~m}$ w.e.). Because impurity concentrations are always positive but show an asymmetry towards large values (e.g. Bigler et al., 2010), we use the logarithm of the $\mathrm{Ca}++$ concentration in all cases.

As a first step in the statistical analysis, the depth dependence of the density variability and that of the $\mathrm{Ca}++/$ density relationship were analyzed on a $5 \mathrm{~m}$ w.e. running window. For this analysis, the standard deviation and Pearson correlation were used as measures of variability and of the $\mathrm{Ca}++-$ density relationship, respectively. As the density and $\mathrm{Ca}++$ analysis were performed on different measurement devices, a slight depth uncertainty cannot be excluded. This was accounted for by calculating the maximum cross correlation in a $20 \mathrm{~mm}$ w.e. window instead of a single correlation estimate. For each analyzed firn core, the significance limits of the running correlation, including the depth uncertainty were determined by a Monte-Carlo experiment. In the Monte-Carlo experiment, the chemistry data

Table 1

Locations and references of the analyzed and presented firn cores.

\begin{tabular}{|c|c|c|c|c|c|c|}
\hline $\begin{array}{l}\text { Firn } \\
\text { core }\end{array}$ & Lat $^{\circ}$ & Lon $^{\circ}$ & $\begin{array}{l}\text { Elevation } \\
\text { m a.s.l. }\end{array}$ & $\begin{array}{l}\text { Ann. mean Temp. } \\
\left({ }^{\circ} \mathrm{C}\right)\end{array}$ & $\begin{array}{l}\text { Ann. } \\
\text { mean } \\
\text { Accm. } \\
\text { rate } \\
\text { m w.e. }\end{array}$ & Reference \\
\hline B20 & 78.833 & -36.500 & 2147 & & 0.099 & $\begin{array}{l}\text { Wilhelms, } \\
\text { 1996; } \\
\text { Bigler et } \\
\text { al., } 2002\end{array}$ \\
\hline B29 & 76.0039 & -43.4920 & 2874 & -31.6 & 0.153 & $\begin{array}{l}\text { Wilhelms, } \\
1996\end{array}$ \\
\hline B31 & -75.3489 & -3.2582 & 2669 & -44.3 & 0.063 & $\begin{array}{l}\text { Oerter et } \\
\text { al., } 2000 \text {; } \\
\text { Sommer et } \\
\text { al., } 2000\end{array}$ \\
\hline B32 & -75.0014 & 0.0042 & 2882 & -44.5 & 0.061 & $\begin{array}{l}\text { Oerter et } \\
\text { al., } 2000 \text {; } \\
\text { Sommer et } \\
\text { al., } 2000\end{array}$ \\
\hline B33 & -75.1002 & 6.2991 & 3160 & -46.1 & 0.044 & $\begin{array}{l}\text { Oerter et } \\
\text { al., } 2000 \text {; } \\
\text { Sommer et } \\
\text { al., } 2000\end{array}$ \\
\hline
\end{tabular}


were replaced by surrogate data with the same auto covariance structure, and the correlation analysis is repeated 10,000 times. This enabled the determination of the statistical significance level of correlation for each of the firn cores. We additionally show the results disregarding the depth uncertainty (i.e. calculating the correlation without relative shift in depth of $\mathrm{Ca}++$ relative to the density) to demonstrate that this procedure does not affect the conclusions.

In a second step of our statistical analysis we estimated the wavelet sample spectrum using the Morley wavelet (sowas package, Maraun and Kurths, 2004; Maraun et al., 2007) to analyze the depth dependent behavior of density and chemistry in the frequency domain. Wavelet analysis is a common tool for analyzing localized variations of power within a data series (Torrence and Compo, 1998), even if the dominant modes of variability are non-stationary. It is therefore perfectly suited for our application in which we seek to identify annual cycles and their dependence on firn depth. Local significance was tested against a red noise null hypothesis using Monte Carlo experiments (Maraun et al., 2007). However, one must note that local significance testing will result in spurious significant patches especially as adjacent areas in the wavelet sample spectrum are not independent (Maraun et al., 2007).

The results are quite insensitive on the choice of the interpolation resolution (1-10 $\mathrm{mm}$ ), the low pass filtering method (finite response filter, or spline fit) or the cut-off frequency. Additionally, to investigate potential artifacts caused by the calculation process (conversion to water equivalent scale, interpolation/averaging, filtering and statistical analysis on a moving window), we performed the complete calculation process on a random surrogate dataset. This consisted of the B29 firn core data with density values replaced by a random time series with the same auto covariance structure as the B29 density. The results show that our statistical procedure does not produce any systematic artifacts (Fig. A1).

\section{Results and interpretation}

In the following, we present basic features of the relationship between density and impurities. They are most obvious in the Greenland core B29 (Figs. 1-3). Density and the (logarithm of the) $\mathrm{Ca}++$ concentration are uncorrelated near the surface (Fig. 1, A) but covary in deeper firn (Fig. $1 \mathrm{~B}, \mathrm{C}$ ). The depth interval of the mid panels marks a relative minimum in density variability. The depth interval of the lower panel is characterized by increased density variability (i.e. secondary maximum in density variability). Here, at $30 \mathrm{~m}$ w.e. depth, density exhibits a strong seasonal cycle that is nearly indistinguishable from the seasonal cycle of the $\mathrm{Ca}++$ concentration. This strong relationship between the chemical and physical properties is not limited to the seasonal cycle but is also seen in the slower variations such as the coherent inter-annual variability in the seasonal cycle amplitudes of $\mathrm{Ca}++$ and density. Density variability increases approximately linearly with the logarithm of the $\mathrm{Ca}++$ concentration in this depth interval (Fig. 2).

The $\mathrm{Ca}++$ variability, including its annual cycle, is unlikely to arise due to the density changes because the annual cycle of the $\mathrm{Ca}++$ concentration is seen throughout the core while the seasonal cycle in density arises only in a specific depth interval. Furthermore, $\mathrm{Ca}++$ shows a constant phase relationship over entire firn core records with other parameters such as particulate dust concentration (as $\mathrm{Ca}++$ is largely dust derived), which is considered an immobile impurity within the firn and ice matrix (Rasmussen et al., 2006). We therefore propose that the density variability is altered with depth and adapts to the $\mathrm{Ca}++$ concentration signal. The positive correlation (i.e. high $\mathrm{Ca}++$ concentration coincidences with high density, Figs. 1C and 2) suggests that increased impurity concentrations produce a softening in the ice and thus an increased densification because of enhanced creep. We hypothesize that density in deeper firn has lost its memory of the initial layering at the surface. Characteristic features of the
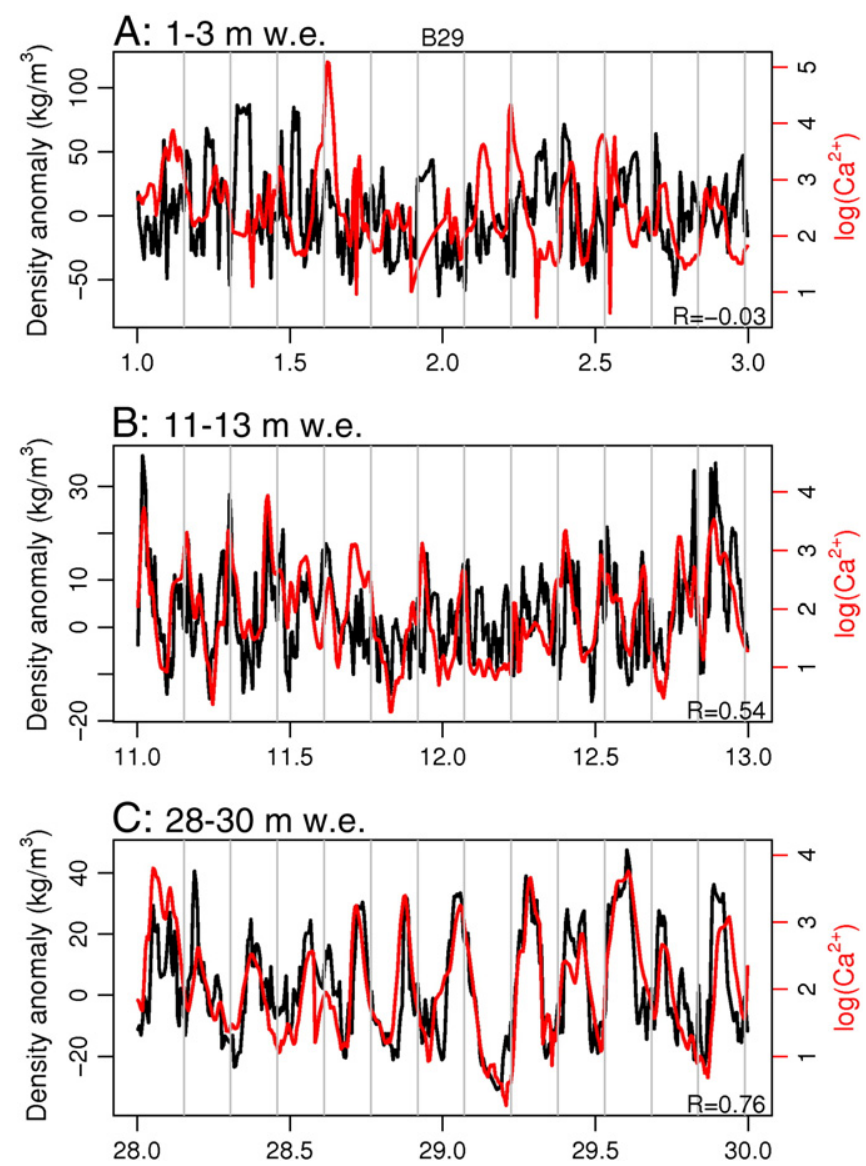

Fig. 1. Detailed density profiles (black line) over two meter-intervals and the logarithmized $\mathrm{Ca}++$ ion concentration (red line, in $\mathrm{ng} / \mathrm{g}$ ) of the B29 firn core at the surface (A), the minimum of the density variability (B) and the secondary maximum of density variability (C)

snow pack in terms of density, originating from the deposition or processes close to the surface (e.g. soft or hard snow, or the existence of depth hoar layers) are overprinted by the effect of impurities.

The statistical analysis of the evolution of the density variability and the density-impurity relationship with depth (Fig. 3, upper panel) underlines this finding. At the surface, the density variability is highest and the correlation of density and $\mathrm{Ca}++$ is negligible.

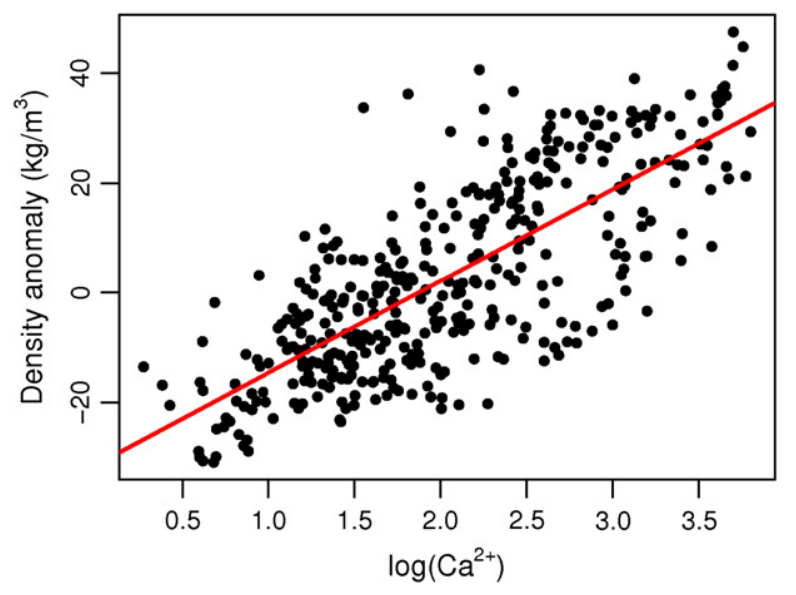

Fig. 2. Scatter plot of the density variability and the logarithmized $\mathrm{Ca}++$ concentration (ng/g) in the depth interval of the secondary maximum density variability of B29. 

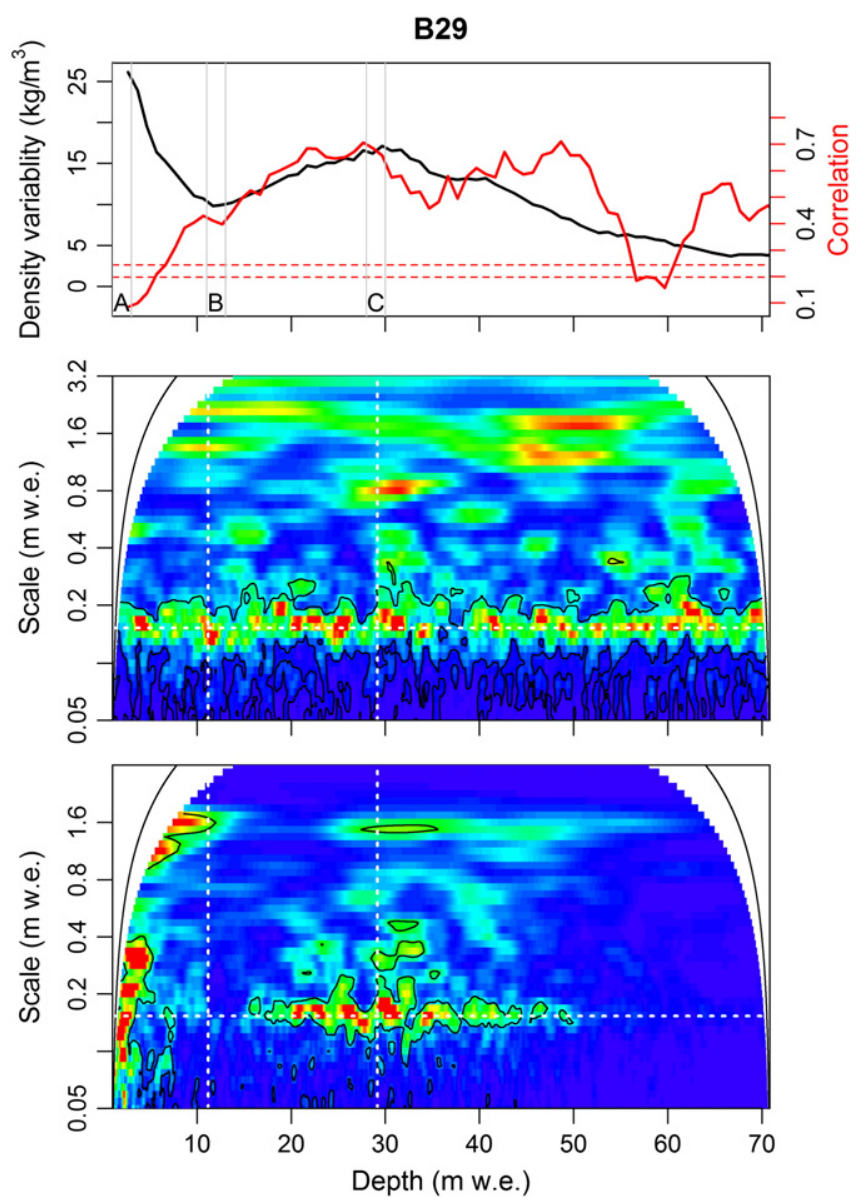

Fig. 3. Density variability and density-Ca ++ correlation coefficient (upper panel) and wavelets spectra of $\mathrm{Ca}++$ concentration (middle panel) and density (lower panel) of the B29 firn core. Upper panel: Dotted horizontal lines mark the 95\% and 99\% confidence level in the upper panel. The three depth intervals of Fig. 1 are indicated. The green line shows the correlation disregarding the depth uncertainty. Mid and lower panel: The dashed vertical lines mark the position of the relative minimum and secondary maximum of the standard deviation of density. The frequency of the accumulation rate is marked by a horizontal dashed line and point wise significant areas with black contours.

From the surface to $10 \mathrm{~m}$ w.e. depth, the density variability decreases whereas the correlation between $\mathrm{Ca}++$ and density increases. The correlation reaches its highest values $(r=0.7)$ in the depth where the density variability shows the secondary maximum (around $30 \mathrm{~m}$ w.e. depth). Finally, at greater depths, as the density approaches the ice density, the variability of the firn density decreases. The strong correlation between impurities and density remains constant until it gets weaker at around 50-60 $\mathrm{m}$ w.e. depth (Fig. 3, upper panel). This instability is probably caused by the reduced signal to noise ratio as the amplitude of the density variations is strongly reduced, while the measurement error of density is constant (Wilhelms, 1996, 2000).

The wavelet analysis of the records complements the study by showing the evolution of $\mathrm{Ca}++$ concentration and density of B29 in the frequency domain (Fig. 3, mid and lower panel). Significant spectral energy in the frequency band of the mean annual accumulation rate $(\sim 150 \mathrm{~mm}$ w.e./a) is present in the $\mathrm{Ca}++$ concentration in the entire record (mid panel). In contrast, the density data show a significant annual cycle only between 20 and $40 \mathrm{~m}$ w.e. depth (lower panel), consistent with the findings in the depth domain (Fig. 1). We hypothesize that with increasing depth, $\mathrm{Ca}++$, or more generally impurities, affect densification and begin to control the variability of density.
From these first results we cannot identify the precise impurity species affecting densification. However, in Greenland firn the various species show clear differences in the seasonal phasing (Beer et al., 1991; Fischer and Wagenbach, 1996; Whitlow et al., 1992), so we can conclude that the impurity effect on density results from a signal with the same seasonal phasing as $\mathrm{Ca}++$. A possible candidate could be particulate mineral dust. The observation that not only the seasonal cycle, but also inter-annual variations co-vary between density and $\mathrm{Ca}++$ (Fig. 1c), further constrains the choice of the driving impurity species.

The remaining four cores show the same relationship between $\mathrm{Ca}++$ and density as B29 (Fig. 4 upper panel, supplement Figs. A2-A5). Like in core B29, $\mathrm{Ca}++$ and density are uncorrelated at the surface. With depth, a significant correlation between the $\mathrm{Ca}++$ concentration and the density develops. In the deeper firn the magnitude of the correlation of core B20 from Northeast Greenland is comparable to B29. In the three Antarctic cores, the correlation values are lower, but are still highly significant $(\mathrm{p}<0.01)$ in most parts of the deeper firn. This weaker and less stable correlation can be explained by the reduced data quality caused by lower accumulation and the lower impurity concentrations. Further, both the density and the impurity data have missing sections and show outliers that might be artifacts of the measurements. Another potential cause for the lower correlation between density and $\mathrm{Ca}++$ in Antarctic firn could be that $\mathrm{Ca}++$ is not the ultimate cause of the faster densification, but some other $\mathrm{Ca}++$ related impurity such as particulate dust. In contrast to Greenland, $\mathrm{Ca}++$ levels in Antarctica are to a large part sea salt derived (>50\%) for modern conditions (Bigler et al., 2006; Fischer et al., 2007; Sommer et al., 2000). If the true influencing impurity is not $\mathrm{Ca}++$ itself but particulate dust, then a lower correlation is to be expected in modern Antarctic firn, because part of the $\mathrm{Ca}++$ variability is sea salt derived. In glacial times, however, the sea salt contribution to $\mathrm{Ca}++$ becomes also negligible in Antarctica (Bigler et al., 2006; Fischer et al., 2007). This is different for Greenland, where even for modern conditions $\mathrm{Ca}++$ is mainly dust derived.

A clear difference between core B29 and these four cores is seen in the wavelet spectra. Neither density nor $\mathrm{Ca}++$ concentration (Fig. 4 mid panels) shows spectral energy concentrated at the frequency corresponding to the annual cycle in accumulation. At the investigated core sites the accumulation rates vary between 44.3 (B31) and 153 (B29) $\mathrm{mm}$ w.e./year. The accumulation rate shows a distinct interannual variability, which is strongest at the low accumulation rate sites. Accordingly, the poor representation of the seasonal cycle of the climate proxies in the wavelet spectra of low accumulation sites is not a surprising result; it is well known that in low accumulation areas the seasonal cycles of the climate proxies are not well expressed in the depth domain of firn and ice cores because of the inter-annual variability in accumulation. In addition, a lack of horizontal heterogeneity of layers might lead to spatial discontinuities in the deposition of impurities within the firn at a drilling site. Due to wind erosion and redistribution, essentially any signal recorded in ice cores has larger scatter in low accumulation areas than in areas of moderate or high accumulation.

\section{Discussion}

In our study, we identified for the first time a strong influence of impurities (here represented by $\mathrm{Ca}++$ ) on the density variability in firn cores. Our results suggest that with increasing depth and time the impurities severely modify the structure of the initial layering.

The impurity effect has implications for the understanding of firn mechanics, deformation and recrystallization on the micro-scale and the evolution of the microstructure (Kipfstuhl et al., 2009). However, it is particularly relevant for processes governing the air enclosure during glacial climate periods and during climate transitions, and 
B20
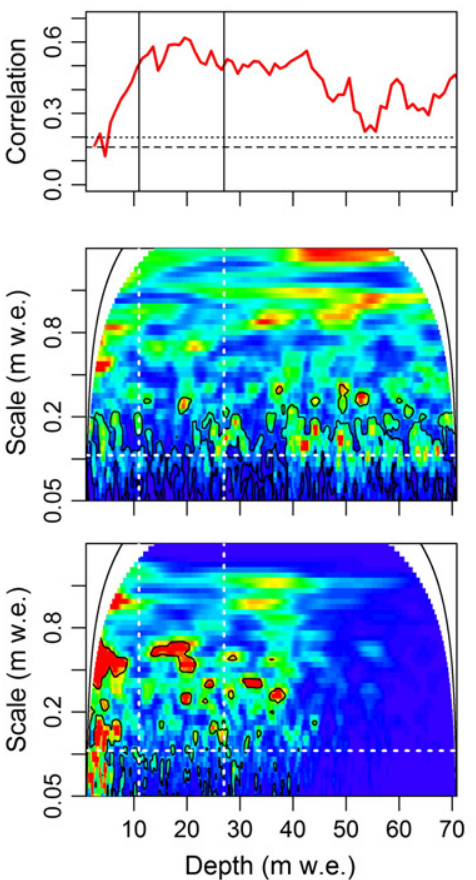

B31
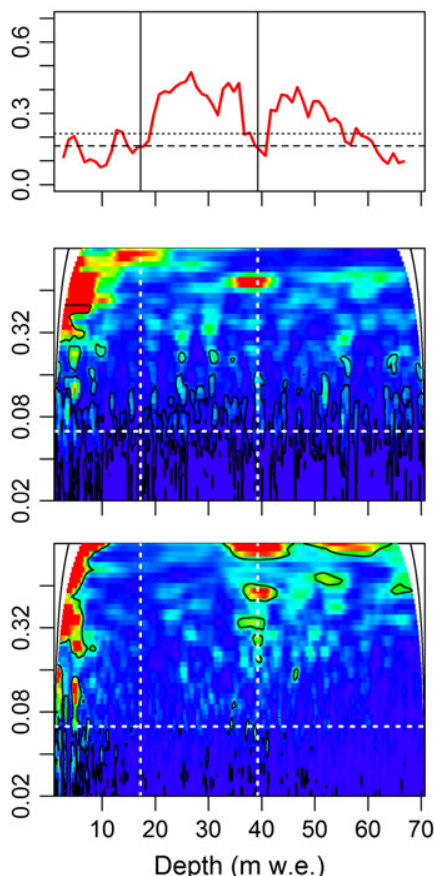

B32
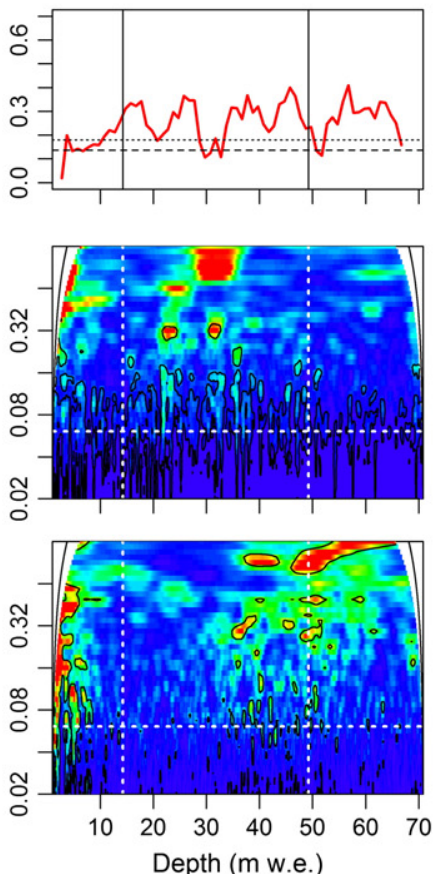

B33
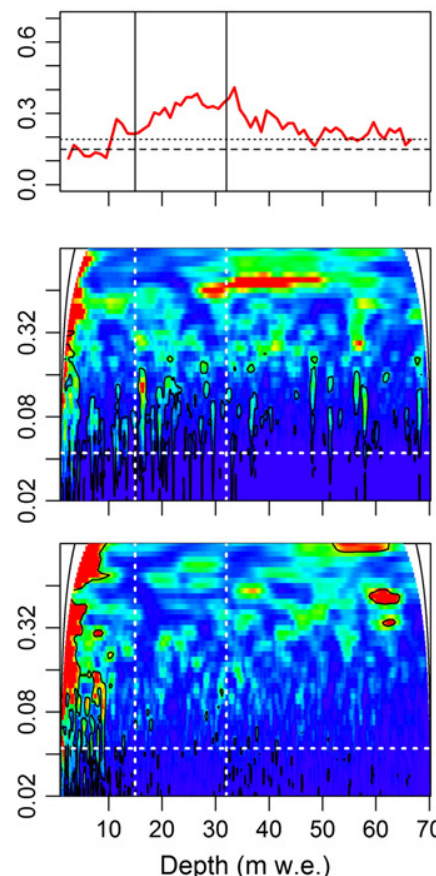

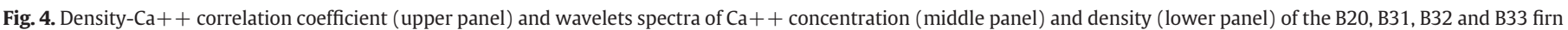
cores. Dashed lines as described in caption of Fig. 3.

therefore may have implications for paleo-climate reconstructions. The new findings suggest a need to revise the explanation given for the evolution of the variability in density in firn in former publications including the work of the authors of this study.

Most likely the differences in densification rates of layers with initially varying densities still play some role in the upper meters but lose influence with depth and time. This is based on the finding that in the depth of the relative minimum of the variability, the correlation between density and $\mathrm{Ca}++$ reaches values already close to its maximum values (Figs. 1, 3, 4). A first statistical estimate of the impurity effect, derived by removing the density variability linearly related to $\mathrm{Ca}++$, shows that without the impurity effect, the increase of the density variability with depth would be strongly reduced (Fig. 5). This is a conservative estimate of the impurity influence, as measurement noise on both measurements reduces the $\mathrm{Ca}++$ /density relationship. Detailed microstructural analyses are needed, to better

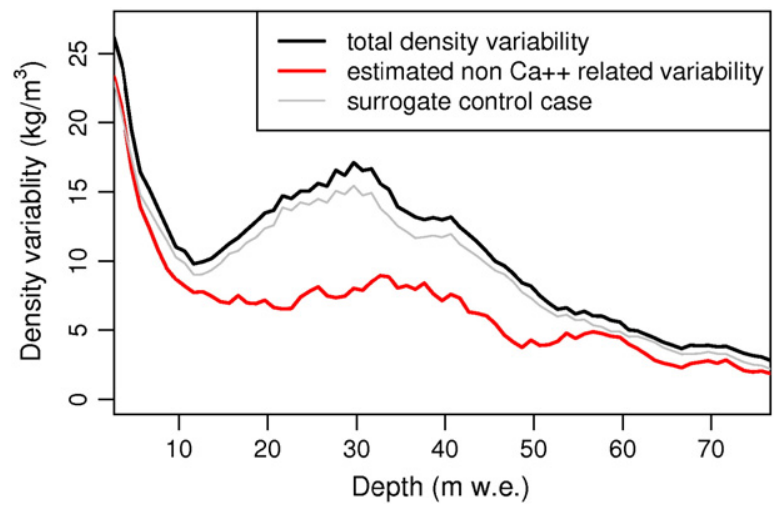

Fig. 5. Estimate of the density variability unrelated to the impurity effect. The nonimpurity density variability is estimated by removing the part which can be explained by a linear relationship to $\log (\mathrm{Ca}++)$. This is performed in a moving window with $1 \mathrm{~m}$ depth, and the fitting allows for $\mathrm{a}+-50 \mathrm{~mm}$ depth uncertainty. To quantify the bias of this method, the $\mathrm{Ca}++$ time series is replaced by a random surrogate and the analysis is repeated (gray line). discriminate the structure induced effect on densification from the impurity effect on densification.

Our results suggest that with increasing depth firn loses its memory of the original density layering reflecting the deposition history. The structure of the layering at the firn-ice transition may therefore be dominated by the local distribution of the impurities. It can be assumed, that deeper and older ice was initially affected by impurities as well, since glacial ice for example shows high and strongly varying impurity content. However, these assumptions need to be verified for sites with very low accumulation rates.

An impurity influence on the densification will likely affect the glacial predictions of firn models. For example, firn models that are tuned to the modern relationship of temperature and firn properties predict a Greenland Summit density profile at the LGM similar to that observed today at Dome C (Antarctica) (Arnaud et al., 2000). However, in glacial firn, the impurity concentration at Summit was 10-100 times higher than it is today. Our new results would suggest that we can expect softening and faster densification than assumed in the model. However, $\delta{ }^{15} \mathrm{~N}_{2}$ measurements performed on glacial Greenland ice, which reflect the changes in the diffusive column length of the firn, agree rather well with the firn depth predicted by firnification models (Landais et al., 2006). This apparently limits the influence of $\mathrm{Ca}^{++}$concentrations on glacial densification in Greenland. The negative correlation of temperature and accumulation rate with impurity content (i.e. high temperature and high accumulation rate with low dust content and vice versa) may explain why the impurity effect has not been observed earlier in the data and why the model results agree with the observations.

However, at Antarctic low accumulation sites, where $\mathrm{Ca}++$ concentrations also increase by 1-2 orders of magnitude, the glacial bubble close-off depth is notoriously over-predicted by firn models (Landais et al., 2006). The impurity effect may therefore contribute to solving the problem of the mismatch between predicted and observed depths of firn-ice transitions determined from gas records (Dreyfus et al., 2010; Sowas et al., 1992). A quantitative estimate of the impurity effect on bubble enclosure cannot be achieved at this point and requires more dedicated research efforts. Nevertheless, 
the evidenced loss of information about surface layering in the course of the impurity influenced densification questions hypotheses invoking an effect of surface irradiation on the firn layering at bubble closeoff.

An explanation for the possible link between impurity content and densification is beyond the scope of this paper and can only be discussed in a speculative way. Observations and models of impurity effect on grain growth in deep ice (Alley, 1988; Durand et al., 2006) may not apply here since the impurity effect in the porous firn column needs to be considered instead of the effects described in the ice matrix.

Polar firn impurities consist of soluble contents and microparticles and both can be thought to alter the density of the firn. In principle there are two ways how an increased solute concentration may influence the intermediate densification below $12 \mathrm{~m}$ w.e. depth and the bubble close-off. Doping the individual (mono-crystalline) snow grains with ionic impurities generally increases the ductility of ice, i.e. its creep (Kang, 2005). Thus, layers with higher impurity content can in principle densify faster.

Alternatively, the impurity content in terms of particulate dust is assumed to be localized at the grain boundaries and triple junctions. It may therefore increase the thickness of the quasi-liquid layer coating of individual grains. The migration of this quasi-liquid by capillary forces has been hypothesized to contribute to the sintering process during firn densification (Dash, 1989; Dash et al., 2006). Thus, higher impurity content at the grain boundaries would lead to an acceleration of the densification process. A detailed theoretical assessment of these phenomena is not possible here; however, recent studies of the location of impurities in poly-crystalline ice point to larger impurity concentrations at the grain boundaries and smaller ones in the bulk of the snow grains (Durand et al., 2006). Obviously this is dependent on the ionic species considered but overall could support the quasi-liquid layer effect to be a possible explanation for the observed faster densification of high impurity layers in polar firn.

\section{Conclusions}

By analyzing high resolution density and $\mathrm{Ca}++$ profiles in 5 firn cores from Greenland and Antarctica, we show for the first time that impurities have a significant impact on firn densification.

The covariance of density and the $\mathrm{Ca}++$ concentration in deeper firn implies:

1. Impurities affect densification over a wide range of concentrations and lead to a softening of the firn. This is manifested by an increasing correlation of $\mathrm{Ca}++$ and density from the surface into deeper firn, observed at all investigated cores, independent on the local climatic conditions reflected by the core sites (see Table 1 ). The impurity effect is most obvious for the high-accumulation site in Greenland and less clear but still significant for the Antarctic, low accumulation sites.

2. Impurities change the character of the firn layering from deposition-dominated density layering in the upper firn to impurity-dominated density layering in the deeper firn and at the firn-ice transition. The observed development of seasonal cycles in density, which increase with depth and which follow the $\mathrm{Ca}++$ seasonality, shows that strong seasonal cycles in impurities can induce a seasonal cycle in firn density unrelated to the temperature. This contradicts the hypothesis that the deep firn seasonal density cycle is induced by temperature at the surface (for example Landais et al., 2006; Zwally and Li, 2002). The relative maximum in density variability in deeper firn (Freitag et al., 2004; Gerland et al., 1999; Hörhold et al., 2011) can likely be attributed to the impurity effect.

3. The impurity effect may also have ramifications for the interpretation of precessional $02 / \mathrm{N} 2$ variations found in records derived from air bubbles in polar ice (Bender, 2002; Kawamura et al., 2007). These variations are caused by size-dependent fractionation during the bubble close-off (Huber et al., 2006). Fujita et al. (2009) link the initial layering at the surface (i.e. summer and winter layers) and the strength of insolation with the gas transport processes at close-off and the measured $02 / \mathrm{N} 2$ ratios. Our results suggest that an initial seasonal density-layering loses its initial stratigraphic information in the top $10-15 \mathrm{~m}$ of the firn column. Therefore a direct line of influence of the local radiation balance on the surface snow density cannot be the ultimate reason for the observed 02/N2 fractionation at close-off depth. Thus, a direct link between density and air bubbles in polar ice cannot be provided. Certainly our results do not give an alternative explanation but an indirect influence of the impurities on the air enclosure process needs to be discussed in the future.

4. Simplifications, presently used in firn densification models, e.g. homogeneous firn without layering or calibration to modern firn, are critical assumptions for modeling firnification during glacial climate conditions. Firn models that use the modern spatial relationship as an estimate for the temporal relationship predict slower densification with decreasing temperature. Our data imply that layers with high impurity concentrations reach the critical density of pore close-off first. Following our observations the 10-100 fold increase in impurity concentrations during glacial periods implies a softer firn at least in Antarctica. This could be one reason why the depth of the firn-ice transition and the ice-age gas-age difference may be overestimated during glacial periods and climatic transitions.

Although, we identified an impurity densification relationship using $\mathrm{Ca}++$, this species is not necessarily the direct modulator of firn densification. In future work, we will seek to identify other impurity species that co-vary with $\mathrm{Ca}++$ in Greenland as alternative candidates (such as particulate dust). The mechanism for impurity driven modulation of the densification remains unclear and is an important area for future investigations.

Supplementary materials related to this article can be found online at doi:10.1016/j.epsl.2011.12.022.

\section{Acknowledgment}

This work is funded by the Deutsche Forschungsgemeinschaft (DFG) grant FR2527/1-1. We thank the field team of the NorthGreenland traverse 1993-1995 and Hans Oerter and the team of the DML-pre-site survey 1997/1998. We warmly thank Zan Stine for excellent assistance with the manuscript.

\section{References}

Alley, R.B., 1988. Concerning the deposition and diagenesis of strata in polar firn. J. Glaciol. 34, 283-290.

Arnaud, L., Barnola, J.-M., Duval, P., 2000. Physical modeling of the densification of snow/firn and ice in the upper part of polar ice sheets. In: Hondoh, T. (Ed.), Physics of Ice Core Records, pp. 285-305. Sapporo.

Beer, J., Finkel, R.C., Bonani, G., Gäggeler, H., Glach, U., Jacob, P., Klockow, D., Langway, C.C.J., Neftel, A., Oeschger, H., Schotterer, U., Schwander, J., Siegenthaler, U., Suter, M., Wagenbach, D., Wölfli, W., 1991. Seasonal variations in the concentrations of ${ }^{10} \mathrm{Be}, \mathrm{Cl}^{-}, \mathrm{NO}_{3}^{-}, \mathrm{SO}_{4}^{2-}, \mathrm{H}_{2} \mathrm{O}_{2},{ }^{210} \mathrm{~Pb},{ }^{3} \mathrm{H}$, mineral dust, and $\delta^{18} \mathrm{O}$ in Greenland snow. Atmos. Environ. 25, 899-904.

Bender, M.L., 2002. Orbital tuning chronology for the Vostok climate record supported by trapped gas composition. Earth Planet. Sci. Lett. 204 (1-2), 275-289 30.

Bigler, M., Wagenbach, D., Fischer, H., Kipfstuhl, S., Miller, H., Sommer, S., Stauffer, B. 2002. Sulphate record from a northeast Greenland ice core over the last 1200 years based on continuous flow analysis. Ann. Glaciol. 35, 250-256.

Bigler, M., Röthlisberger, R., Lambert, F., Stocker, T.F., Wagenbach, D., 2006. Aerosol deposited in East Antarctica over the last glacial cycle: detailed apportionment of continental sea-salt contributions. J. Geophys. Res. 111, D08205. doi:10.1029/ 2005JD006469.

Bigler, M., Röthlisberger, R., Lambert, F., Wolff, E.W., Castellano, E., Udisti, R., Stocker, T.F., Fischer, H., 2010. Atmospheric decadal variability from high-resolution Domce C ice core records of aerosol constituents beyond the Last Interglacial Quatern. Sci. Rev. 29, 324-337. 
Bloomfeld, P., 1976. Fourier Analysis of Time series: An introduction. John Wiley \& Sons Inc, pp. $1-272$.

Dash, J.G., 1989. Surface melting. Contemp. Phys. 30, 89-100.

Dash, J.G., Rempel, A.W., Wettlaufer, J.S., 2006. The physics of premelted ice and its geophysical consequences. Rev. Mod. Phys. 78, 695-741.

Dreyfus, G.B., Jouzel, J., Bender, M.L., Landais, A., Masson-Delmotte, V., Leuenberger, M. 2010 . Firn processes and $\delta 15 \mathrm{~N}$ : potential for a gas-phase climate proxy. Quat. Sci. Rev. 29, 28-42.

Durand, G., Weiss, J., Lipenkov, V., Barnola, J.M., Krinner, G., Parrenin, F., Delmonte, B. Ritz, C., Duval, P., Röthlisberger, R., Bigler, M., 2006. Effect of impurities on grain growth in cold ice sheets. J. Geophys. Res. 111 (F1), 1-18.

Fischer, H., Wagenbach, D., 1996. Large-scale spatial trends in recent firn chemistry along an east-west transect through central Greenland. Atmos. Environ. 30, 3227-3238.

Fischer, H., Siggaard-Andersen, M.-L., Ruth, U., Röthlisberger, R., Wolff, E., 2007. Glacial/ Interglacial changes in mineral dust and sea salt records in polar ice cores: sources, transport, deposition. Rev. Geophys. 45. doi:10.1029/2005RG000192.

Freitag, J., Wilhelms, F., Kipfstuhl, S., 2004. Microstructure-dependent densification of polar firn derived from x-ray microtomography. J. Glaciol. 30, 243-250.

Fujita, S., Okuyama, J., Hori, A., Hondoh, T., 2009. Metamorphism of stratified firn at dome Fuji, Antarctica: A mechanism for local insolation modulation of gas transport conditions during bubble close off. J. Geophys. Res. 114, F03023. doi:10.1029/2008JF001143.1-21.

Gerland, S., Oerter, H., Kipfstuhl, S., Wilhelms, F., Miller, H., Miners, W.D., 1999. Density log of a $181 \mathrm{~m}$ long ice core from Berkner Island, Antarctica. Ann. Glaciol. 29, 215-219.

Goujon, C., Barnola, J.-M., Ritz, C., 2003. Modeling the densification of polar firn including heat diffusion: Application to close-off characteristics and gas isotopic fractionation for Antarctica and Greenald sites. J. Geophys. Res. 108. doi:10.1029/ 2002JD003319, 1-18.

Gow, A.J., 1965. On the accumulation and seasonal stratification of snow at the South Pole. J. Glaciol. 5, 467-477.

Herron, M.M., Langway, C.C., 1980. Firn densification: an empirical model. J. Glaciol. 25, 373-385.

Hörhold, M.W., Kipfstuhl, S., Wilhelms, F., Freitag, J., Frenzel, A., 2011. The densification of layered polar firn. J. Geophys. Res. 116, F01001. doi:10.1029/2009JF001630.

Hori, A., Tayuki, K., Narita, H., Hondoh, T., Fujita, S., Kameda, T., Shoji, H., Azuma, N., Kamiyama, K., Fujii, Y., Motoyama, H., Watanabe, O., 1999. A detailed density profile of the Dome Fuji (Antarctica) shallow ice core by X-ray transmission method. Ann. Glaciol. 29, 211-214.

Huber, C., Beyerle, U., Leuenberger, M., Schwander, J., Kipfer, R., Spahni, R., Severinghaus, J.P., Weiler, K., 2006. Evidence for molecular size dependent gas fractionation in firn air derived from noble gases, oxygen, and nitrogen measurements. Earth Planet. Sci. Lett. 243, 61-73.

Kameda, T., Shoji, H., Kawada, K., Watanabe, O., Clausen, H.B., 1994. An empirical relation between overburden pressure and firn density. J. Glaciol. 20, 87-94.

Kang, S.-J.L., 2005. Sintering - Densification, Grain Growth and Microstructure Elsevier Butterworth-Heinemann, Oxford, UK, pp. 1-261.

Kawamura, K. 2009. Accurate chronology for Antarctic ice cores on orbital time scales. PAGES News, vol 17, No 1.

Kawamura, K., Parrenin, F., Lorraine, L., Uemura, R., Vimeux, F., Severinghaus, J.P. Hutterli, M.A., Nakazawa, T., Aoki, S., Jouzel, J., Raymo, M.E., Matsumoto, K., Nakata, H., Motoyama, H., Fujita, S., Goto-Azuma, K., Fujii, Y., Watanabe, O., 2007. Northern Hemisphere forcing of climatic cycles in Antarctica over the past 360,000 years. Nat. Lett. 448. doi:10.1038/nature06015.

Kipfstuhl, S., Faria, S.H., Azuma, N., Freitag, J., Hamann, I., Kaufmann, P., Miller, H., Weiler, K., Wilhelms, F., 2009. Evidence of dynamic recrystallization in polar firn. Geophys. Res. 114, B05204. doi:10.1029/2008JB005583, 1-10.
Landais, A., Barnola, J.M., Kawamura, K., Caillon, N., Delmotte, M., Van Ommen, T., Dreyfus, G., Jouzel, J., Masson-Delmotte, V., Minster, B., Freitag, J., Leuenberger, M., Schwander, J., Huber, C., Etheridge, D., Morgan, V., 2006. Quat. Sci. Rev. 25, 49-62.

Loulergue, L., Parrenin, F., Blunier, T., Barnola, J.-M., Spahni, R., Schilt, A., Raisbeck, G., Chappellaz, J., 2007. New constraints on the gas age-ice age difference along the EPICA ice cores, 0-50 kyr. Clim. Past 3, 527-540.

Maraun, D., Kurths, J., 2004. Cross wavelet analysis: significance testing and pitfalls. Non-linear process. Geophysics 11 (4), 505-514.

Maraun, D., Kurths, J., Holschneider, M., 2007. Nonstationary Gaussian processes in wavelet domain: synthesis, estimation and significance testing. Phys. Rev. E 75, 016707.

Oerter, H., Wilhelms, F., Jung-Rothenhäusler, F., Göktas, F., Miller, H., Graf, W., Sommer, S., 2000. Accumulation rates in Dronning Maud land, Antarctica, as revealed by dielectrical- profiling measurements of shallow firn cores. Ann. Glaciol. 30, 27-34.

Rasmussen, S.O., Andersen, K.K., Svensson, A.M., Steffensen, J.P., Vinther, P.M., Clausen, H.B., Andersen, M.-L.S., Johnsen, S.J., Larsen, L.B., Bigler, M., Röthlisberger, R., Fischer, H., Goto-Azuma, K., Hansson, M.E., Ruth, U., 2006. A new Greenland ice core chronology for the last glacial termination. J. Geophys. Res. 111, D06102. doi:10.1029/2005JD006079.

Raynaud, D., Lipenkov, V., Lemieux-Dudon, B., Duval, P., Loutre, M.-F., Lhomme, N., 2007. The local insolation signature of air content in Antarctic ice. A new step toward an absolute dating of ice records. Earth Planet. Sci. Lett. 261, 337-349.

Salamantin, A.N., Lipenkov, V.Y., Barnola, J.M., Hori, A., Duval, P., Hondoh, T., 2006. Physics of Ice Core Records 2. In: Hondoh, T. (Ed.), Low Temperature Sciences, Supplement Issue, vol. 68, pp. 195-222.

Schwander, J., Sowers, T., Barnola, J.-M., Blunier, T., Fuchs, A., Malaize, B., 1997. Age scale of the air in the summit ice: implication for glacial-interglacial temperature change. J. Geophys. Res. 102, 45-47.

Sommer, S. 1996. Hochauflösende Spurenstoffuntersuchungen an Eisbohrkernen aus NordGrönland, Diploma thesis, Abteilung für Klima- und Umweltphysik, Physikalisches Institut, Universität Bern.

Sommer, S., Wagenbach, D., Mulvaney, R., Fischer, H., 2000. Glacio-chemical study spanning the past $2 \mathrm{kyr}$ on three ice cores from Dronning Maud Land, Antarctica 2. Seasonally resolved chemical records. J. Geophys. Res. 105 (D24) 29,423-29,433.

Sowas, T., Bender, M., Raynaud, D., Korotkevich, Y.S., 1992. D15N of N2 in air trapped in polar ice: a tracer of gas transport in the firn and a possible constraint on ice agegas age differences. J. Geophys. Res. 97 (D14) 15,683-15,697.

Svensson, A., Nielsen, S.W., Kipfstuhl, S., Johnson, S.J., Steffensen, J.P., Bigler, M., Ruth, U., Röthlisberger, R., 2005. Visual stratigraphy of the northern Greenland ice core project (Northgrip) ice core during the last glacial period. J. Geophys. Res. 110, D02108, doi:10.1029/2004JD005134

Torrence, C., Compo, G.P., 1998. A practical guide to wavelet analysis. Bull. Am. Meteorol. Soc. 79 (1), 61-78.

Whitlow, S., Mayewski, P.A., Dibb, J.E., 1992. A comparison of major chemical species seasonal concentration and accumulation at the South Pole and Summit, Greenland. Atmos. Environ. 26, 2045-2054.

Wilhelms, F., 1996. Measuring the conductivity and density of ice cores, 191. Berichte zur Polarforschung, Alfred Wegener Institut für Polar- und Meeresforschung.

Wilhelms, F., 2000. Measuring the dielectric properties of ice cores, 367. Berichte zur Polarforschung, Alfred Wegener Institut für Polar- und Meeresforschung.

Zwally, H.J., Li, J., 2002. Seasonal and interannual variations of firn densification and ice-sheet surface elevation at the Greenland Summit. J. Glaciol. 48, 199-207. 